\title{
A Numerical Study of Water Dump in Aerial Fire Fighting
}

\author{
$\mathrm{KOHYU} \mathrm{SATOH}^{1}$, IWAO MAEDA ${ }^{2}, \mathrm{KUNIO} \mathrm{KUWAHARA}^{3}$, and K.T. YANG ${ }^{4}$ \\ ${ }^{1}$ National Research Institute of Fire and Disaster \\ Mitaka, Tokyo 181-8633, Japan \\ ${ }^{2}$ ShinMaywa Industries. Ltd. \\ Yokohama, Kanagawa 230-0003, Japan \\ 3 Japan Aerospace Exploration Agency \\ Yunodai, Sagamihara, Kanagawa 229-8510, Japan \\ ${ }^{4}$ Department of Aerospace and Mechanical Engineering \\ University of Notre Dame \\ IN 46556, USA
}

\begin{abstract}
In large forest fires over wide areas, aerial fire fighting with water dumping from helicopters and aircrafts has been widely employed in the world, but water dropped from helicopters is not always sufficient to control large fires, since the limited quantity of water that can be carried aloft is a critical issue and also, the duration of aerial fire fighting is necessarily limited to daytime operations. On the other hand, aircrafts can drop large amounts of water, but the aircrafts flying at high-speed and low altitudes are dangerous due to tall buildings, trees and electric power lines. Therefore, aircrafts tend to fly at high altitudes, where the dropping water spreads out as mists in the air. As a result, accurate engineering data on the water supply relative to given fires are critically needed to design the fire-fighting strategies. The objective of this study is to examine the optimum strategies to apply water by the aerial fire fighting. However, tests by real aircrafts to obtain such information would be too costly. Therefore, the patterns of water dumping from aircrafts as well as from helicopters were examined in a first-attempt CFD simulation, together with the investigation of the data in previous real aerial fire fighting tests. It has been found in the CFD simulations that the patterns of dropping water in the air and the corresponding water density on the ground give reasonable results compared to those from the real aerial tests.
\end{abstract}

KEYWORDS: aerial fire fighting, water dump, water tank, drop test, forest fire, fire suppression, optimum strategy, CFD simulation

\section{INTRODUCTION}

Forest fires are of common occurrence all over the world, which cause severe damages to valuable natural environment and loss of human lives. Also large-scale city fires caused by great earthquakes are estimated in such large cities as Tokyo, where many wooden residential houses are built right next to one another. Since fire-fighting options are quite limited in large scale fires over wide areas, the aerial fire fighting with water dumping from helicopters and aircrafts has been widely employed in the world. One problem of such aerial fire fighting is that the duration of aerial fire fighting is necessarily limited to daytime operations, as flights over the mountains and cities in the night are highly dangerous. To prevent the fire spreading, it is obviously important to dump water to the fires as much and as early as possible during the limited daytime. The water dump by helicopters is not always sufficient to control large fires, since the Japanese fire fighting 
helicopters operated by fire departments can carry less than 1.5 tons of water and the quantity of water that can be carried aloft is a critical issue.

Of course, although many helicopters flying parallel can dump totally larger quantities of water, the possibility of collision accidents due to the frequent flights may increase substantially. On the other hand, large amounts of water can be dropped from aircrafts compared to that from helicopters and it takes quite long time to load large amount of water into such aircrafts. However, there is a possibility of deploying flying boats that can carry as much as 15 tons of water scooped from the nearby water body such as sea or lake. The scooping of water from the sea into the body tank takes only 15 seconds with the flying boat gliding on the sea surface. Japan is fortunate in this regard as the sea surrounds it. However, the high-speed flights at low altitudes are generally dangerous over the Japanese mountains, as there may exist tall trees near the ridges and also electric power lines. Therefore, those aircrafts have to fly at much higher altitudes than helicopters, while the dropped water at high altitudes causes water to change into mists in the air, which is useless for fire suppression.

As a result, accurate engineering data on the optimum water dump from helicopters and aircrafts to fires are needed. Particularly, the effects of the flying path, the flying speed, the fire location and strength, and the prevailing wind conditions on the trajectories of the dropping water relative to given fires are critically needed to design the firefighting strategies. Such data are simply not available at the present time and tests by real aircrafts together with even simulated real forest-fire situations to obtain such information would be too costly. The purpose of the present study is to provide some of the needed database, along with the use of a numerical simulation model to predict the flow patterns of the dropping water from the helicopters and aircrafts. Particularly in this study, the patterns of dropping water and the density of water on the ground dropped from a helicopter and a flying boat were examined in CFD simulations, together with the investigation of the data in the previous real aircraft tests.

\section{SIMULATION OF DROPPING WATER FROM A HELICOPTER}

One of the firefighting helicopters employed by Japanese fire departments is the Bell 412-EP, which can carry up to 1 ton of water in a bucket suspended by the helicopter body. Numerical simulations of dropping water from the firefighting helicopter, Bell 412EP, were carried out by using a 3-D unsteady fire model, the same one as that used in our previous studies [1,2]. Briefly, the model, based on the Nagare Code [3,4], is a robust direct finite-difference solver of the complete Navier-Stokes equations, field fire model based on the unsteady Navier-Stokes equations as the governing equations, which is employed in the previous studies $[1,2]$ and will not be detailed here because of space limitations. In the numerical simulations as an approximate model, the helicopter was taken to be stationary, while an opposite wind was supplied over the helicopter with the same value of the flight speed (20 knots, which is approximately $10 \mathrm{~m} / \mathrm{s}$ ) as a boundary condition. The down wash due to helicopter's rotational blades estimated to be $30 \mathrm{~m} / \mathrm{s}$ together with the natural wind supplied in the crosswind direction at $7 \mathrm{~m} / \mathrm{s}$ are used also as boundary conditions. The temperatures of ambient air and water were assumed to be constant at 10 deg Centigrade in the numerical domain and the water quantity to be dropped from the helicopter was 0.8 tons in this study.

It is particularly difficult to model the water splitting from bulk into droplets and splashing at the ground. As an approximation of the behavior of the water droplets 
dispersed in air in the simulations, a heavy gas replaced the water with a density of 800 times that of air, since the density of air is $1.2 \times 10^{-3} \mathrm{~kg} / \mathrm{m}^{3}$ at the normal condition. The artificial heavy gas was supplied at a constant rate of $160 \mathrm{~kg} / \mathrm{s}$ during the 5 seconds from the suspended bucket. The domain height $(\mathrm{H})$ was $21 \mathrm{~m}$ and the numerical grid contained 130 (flight direction) x $65 \times 65(\mathrm{H})$ uniform calculation cells. The bottom exit of the water bucket was located at the height of $12 \mathrm{~m}$ above the ground. The velocity vectors of the dispersing heavy gas is shown in Figs. 1a, b, and $\mathbf{c}$ indicating three different views. The elliptic area depicted on the ground shows the summation of the amount of the heavy gas reaching the ground, which corresponds to the water splashing at the ground after each drop in a time period of 4.5 seconds. These dropping patterns and the areas are reasonably compared with those of video pictures taken in the experiments shown in Fig. 1d. Nevertheless, it also appears from comparing Fig. 1a to Fig. 1d that the water spread in the air has a wider spread in the real dump test than that in the simulations. This is like caused by the lack of a water-droplet breakup model in the simulations. In addition, numerical simulations showed that the effect of downwash at the ground from the helicopter was not particularly significant, as seen in Fig. 1, which is similar to that found in previous experiments by some fire department helicopters [2]. While the authors have investigated the fire fighting strategies, using the CFD simulations of fire spread and fire suppression, it has been found that water less than 1.5 tons dropped from a helicopter is not always sufficient to suppress the large forest fires, based on simulations of forest fire progression [5,6]. As mentioned above, the parallel flights of helicopters may increase the possibility of accidents in the mountains, although many helicopters can carry totally large quantity of water.

(a)

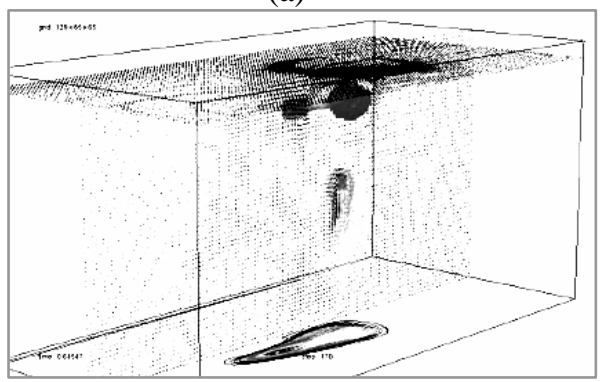

(c)

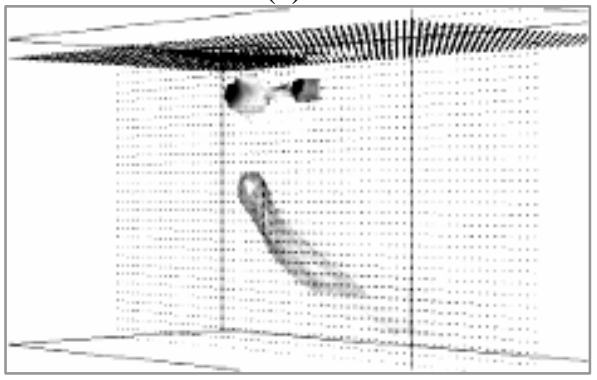

(b)

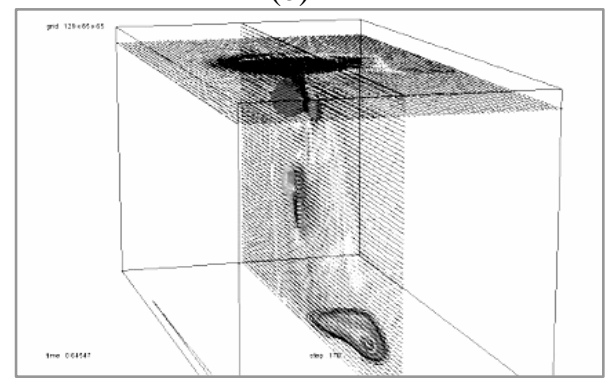

(d)

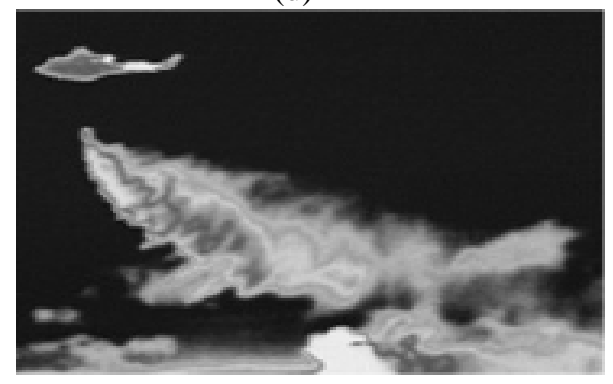

Fig. 1. Simulated dropping water patterns (a) to (c) from a helicopter and dropping pattern (d) in the real dump test. 


\section{SIMULATION OF DROPPING WATER FROM A FLYING BOAT}

Generally, large amounts of water can be dropped from aircrafts larger than helicopters, but it takes quite long time to load large quantity of water into such aircrafts. However, there is a possibility of deploying flying boats, such as PS-1 [6,7], that can carry as much as 15 tons of water scooped from the nearby water body such as sea or lake. The scooping of 15 tons of water from the sea into the tank of PS- 1 takes only 15 seconds. Therefore, the patterns of dropping water and the densities of water on the ground dropped from a flying boat were also examined in CFD simulations, together with the investigation of the data in the previous real aircraft tests [6-8]. It is important to drop water as much and as soon as possible against the fires. For that purpose, 15-ton dropping water pattern from a flying boat was numerically examined in relation to the effective suppression water density $[2,5]$ more than $2 \mathrm{~L} / \mathrm{m}^{2}$.

\section{Simulated Patterns of Dropping Water from a Flying Boat}

The numerical simulation method is the same as that for the firefighting helicopter, as mentioned above. This numerical simulation is based on the following conditions:

(1) Numerical flow domain: $248 \mathrm{~m}$ (L: flight direction) x $59 \mathrm{~m}$ (W: width) x $97 \mathrm{~m}$ (H: vertical direction), as shown in Fig. 2.

(2) Total number of grids: $207(\mathrm{~L}) \times 49(\mathrm{~W}) \times 81(\mathrm{H})=821,583$, with uniform cubic grid size of $1.2 \mathrm{~m}$.

(3) Dimensions of the flying boat: $33 \mathrm{~m}$ (length) $\times 33 \mathrm{~m}$ (width) x $10 \mathrm{~m}$ (height).

(4) The bottom of the body and the exit of the water tank: $85 \mathrm{~m}$ high above the ground.

(5) Dimensions of the opening of the water tank: $1.25 \mathrm{~m}$ (flight direction) $\times 2.5 \mathrm{~m}$ (width).

(6) The heavy gas to model the water component in the air with air density of 800 times heavier than that of the air. The temperatures of ambient air and water: constant at 10 deg Centigrade.

(7) Dropping time: Case 1 for 2.5 seconds at a flow rate of 6 ton/s and Case 2 for 9 seconds at a flow rate of $1.7 \mathrm{ton} / \mathrm{s}$. Quantity of water: totally 15 tons

(8) Boundary conditions: the wind at the left boundary is at the speed of the aircraft (80 knots, namely $148 \mathrm{~km} / \mathrm{h}$ ) and other boundary conditions are all free-slip.

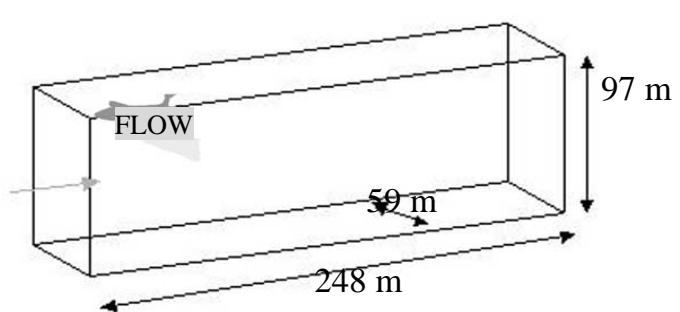

Fig. 2. Flow domain of numerical simulations.

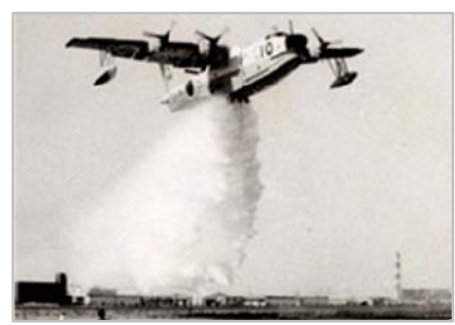

Fig. 3. Dropping pattern from a flying boat PS-1 [6]. 
(a) time $=0.9 \mathrm{sec}$.

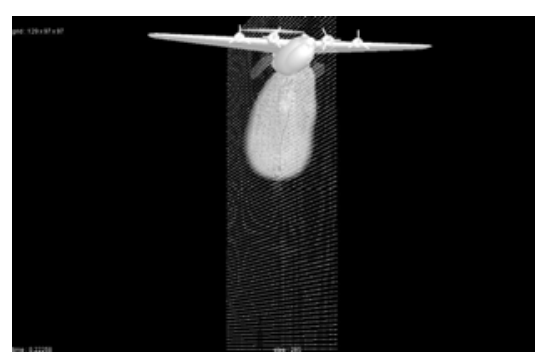

(b) time $=2.0 \mathrm{sec}$.

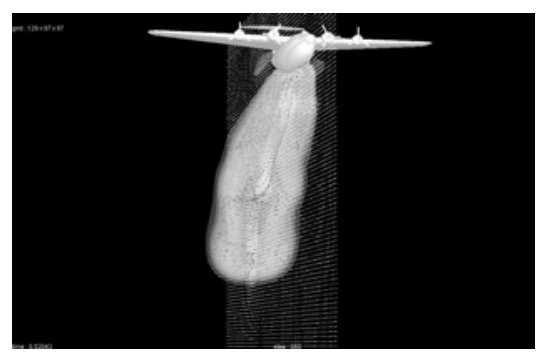

Fig. 4. Front view of the simulated dropping water from a flying boat (Case 1).

(a) Case 1, time $=4.31 \mathrm{sec}$.

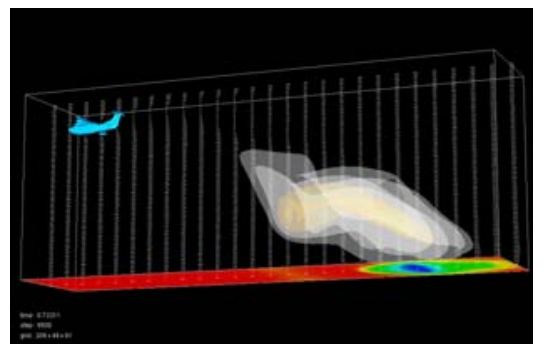

(b) Case 2, time $=4.31 \mathrm{sec}$.

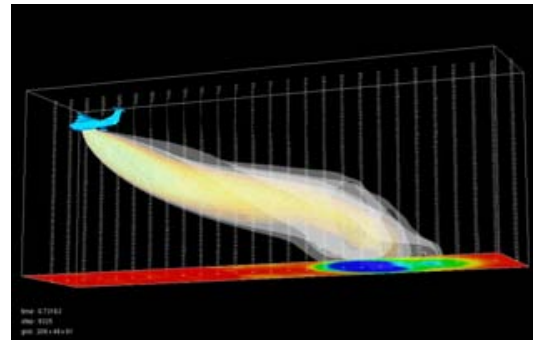

Fig. 5. Simulated pattern of dropping water from a flying boat (Cases 1 and 2).
(1) time $=0.54 \mathrm{sec}$.

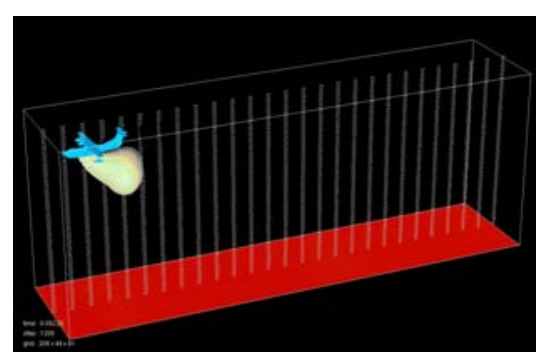

(3) time $=1.79 \mathrm{sec}$.

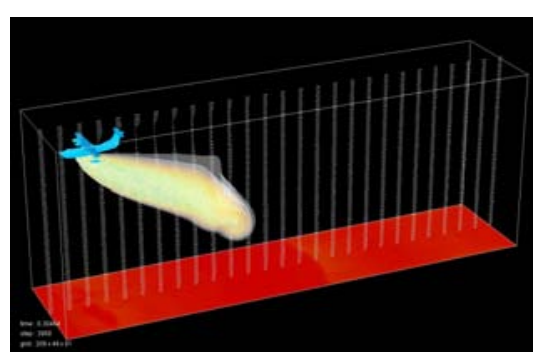

(2) time $=1.18 \mathrm{sec}$.

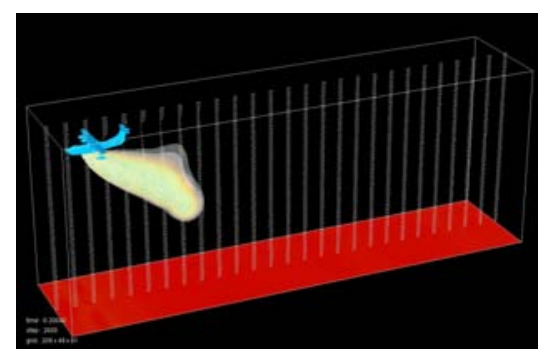

(4) time $=2.42 \mathrm{sec}$.

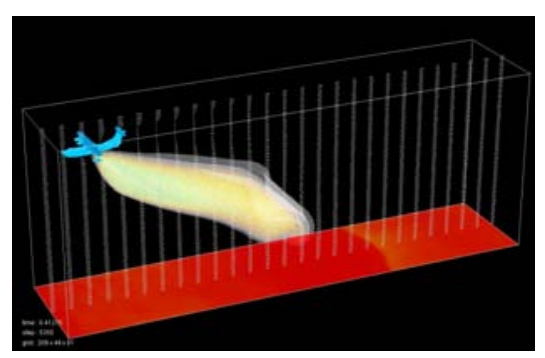


(5) time $=3.06 \mathrm{sec}$.

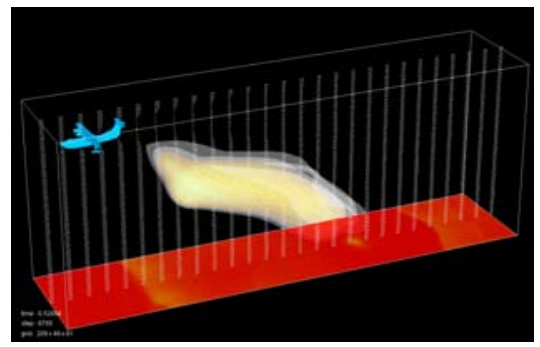

(7) time $=4.76 \mathrm{sec}$.

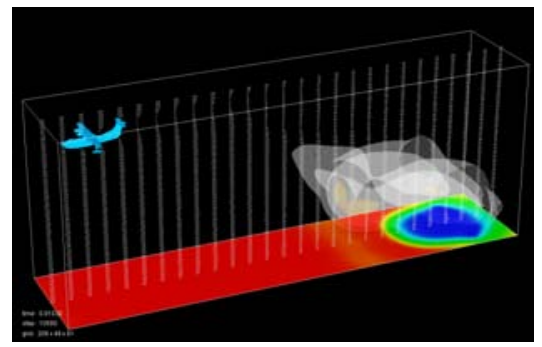

(6) time $=3.76 \mathrm{sec}$.

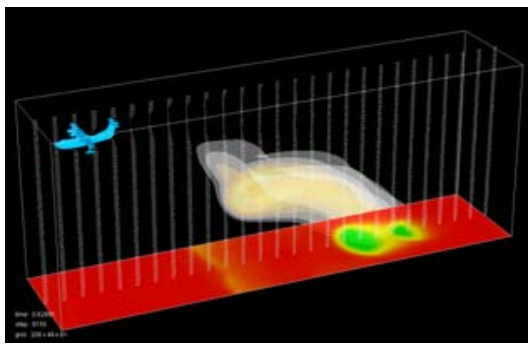

(8) time $=5.76 \mathrm{sec}$.

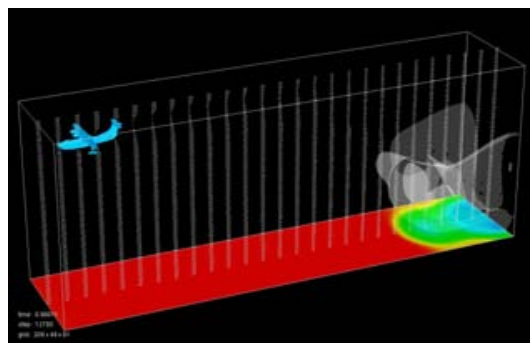

Fig. 6. Simulated time-dependent dropping water patterns for Case 1 (side view).

It should be noted that the free slip conditions imposed here are justifiable due to the fact that in the small volume occupied by the water (i.e., heavy gas), as seen in Figs. 4-6, during the short water drop period, the momentum of the heavy gas is distinctly smaller than that in the cross wind air flow, and consequently the free-slip conditions at the two vertical boundaries of the computational domain are not disturbed by the water drop and therefore the boundary conditions there can be independently described.

We examined whether the simulated flow patterns of water dump from a flying boat are reasonable or not, by comparing it with the dropping water patterns from a flying boat PS-1 (Fig. 3) in the previous study [6]. Figures 4a and b show the front views of the simulated results at time 0.9 seconds and at 2.0 seconds after the dropping water from an exit of the tank. It has been shown that the simulated results of flow patterns of dropping water are rather reasonable, when compared with the real dropping water pattern by a flying boat shown in Fig. 3. Figures $5 \mathrm{a}$ and $\mathrm{b}$ show the simulated patterns, at $t=4.31$ seconds, of dropping water from a flying boat for Cases 1 and 2 where 15 tons of water is dropped during 2.5 seconds and 9 seconds, respectively. The water dropped on the ground for Case 1 is very dense and spreads over a wide area, while the pattern for Case 2 is distributed long and thin on the ground. A much longer numerical domain for Case 2 is needed to calculate the final pattern of water dropped on the ground, since the flow pattern shown in Fig. 5b, indicating the pattern at 4.30 seconds, is still at the half way of 9-second-drop and the location where the dropping water begins is $370 \mathrm{~m}$ farther from the location where the dropping water finishes when the flight speed is $148 \mathrm{~km} / \mathrm{h}$. Figures 6 and 7 show the simulated results of time dependent patterns of dropping water from a flying boat for Case 1, which are the side views and plan views, respectively. The first water (heavy gas) dumped from a flying boat reached the ground at 3.6 seconds after 
the initiation of the water drop. At about 6 seconds after the initiation of the water drop, most water from the flying boat reached the ground.

(a) time $=4.0 \mathrm{sec}$

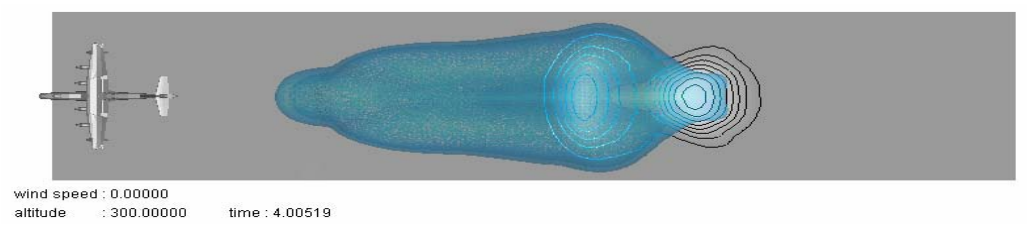

(b) time $=4.5 \mathrm{sec}$

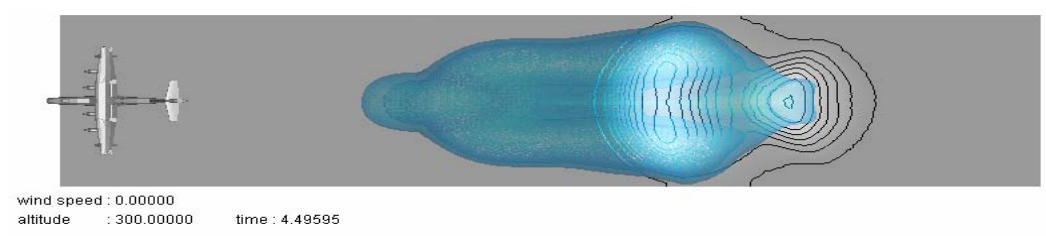

(c) time $=5.0 \mathrm{sec}$

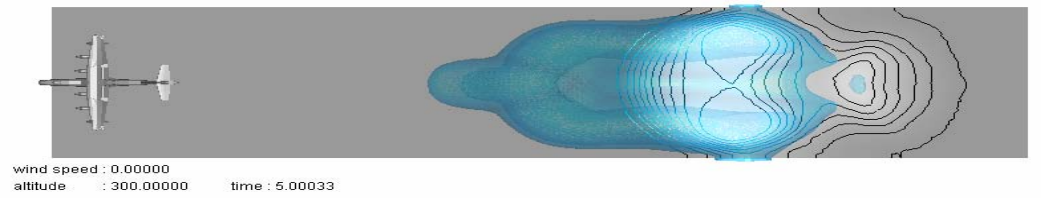

(d) time $=5.5 \mathrm{sec}$
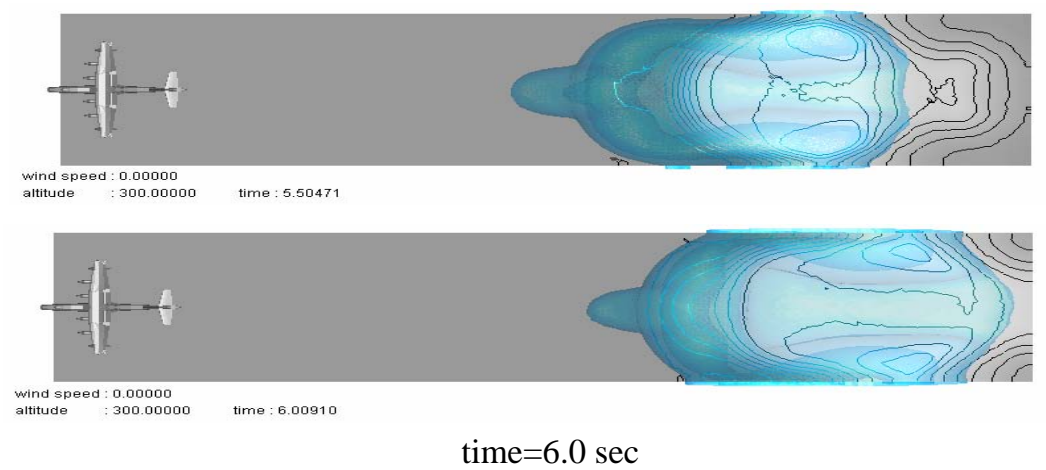

(e)

Fig. 7. Simulated time-dependent dropping water patterns for Case 1 (plan view).

\section{Simulated Area of Dropped Water on the Ground from a Flying Boat}

As seen in Fig. 7e, the simulated area where all 15 tons of dropping water from a flying boat has reached the ground. The length of the water area in the direction of the aircraft flight is also about $100 \mathrm{~m}$ with a width of about $80 \mathrm{~m}$, almost the same as the simulated results in this CFD study. Therefore, the numerical domain has been enlarged twice, both in the directions of the aircraft flight and the width and each cubic grid size is changed from $1.2 \mathrm{~m}$ to $2.4 \mathrm{~m}$. Figure 8 shows the simulated area, by the enlarged numerical domain, where all 15 tons of dropping water based on a flying boat has reached the ground. The length of the dropped water area in the direction of the aircraft flight is about 
$100 \mathrm{~m}$ and the width is about $80 \mathrm{~m}$. Also Fig. 9 is the dropped water area based on the analytical ShinMaywa model based on force and momentum and water-mass balances [7], where the length of the water area in the direction of the aircraft flight is about $100 \mathrm{~m}$ and the width is about $80 \mathrm{~m}$, which are very similar to the simulated results in this CFD study. The coverage area of water density of $2 \mathrm{~L} / \mathrm{m}^{2}$ is about 2,000 to $3,000 \mathrm{~m}^{2}$ in both studies as shown in Figs. 8 and 9. However, both simulation models in this study and in the ShinMaywa study do not account for the water loss, where the dropped water disappears somewhere by changing into mists in the air. Table 1 shows the analyzed data based on the previous studies of the real flying boat tests [6,7], where the flight speed of $148 \mathrm{~km} / \mathrm{h}$ and the flight height of $60 \mathrm{~m}$ provide $40 \%$ water loss and only $60 \%$ water can reach the ground. Therefore, it is important to examine the appropriate height and flight speed in various ambient conditions.

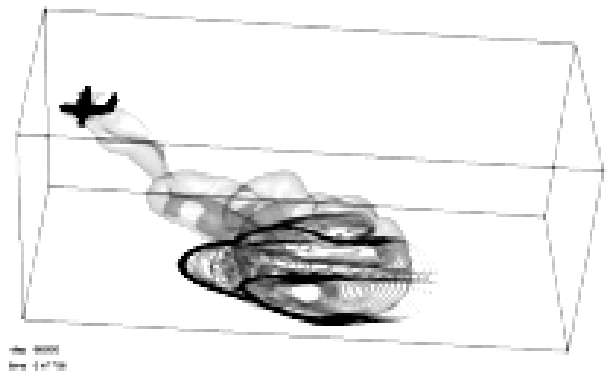

Fig. 8. Simulated area of water dropped from a flying boat for Case 1, where the numerical domain is enlarged.

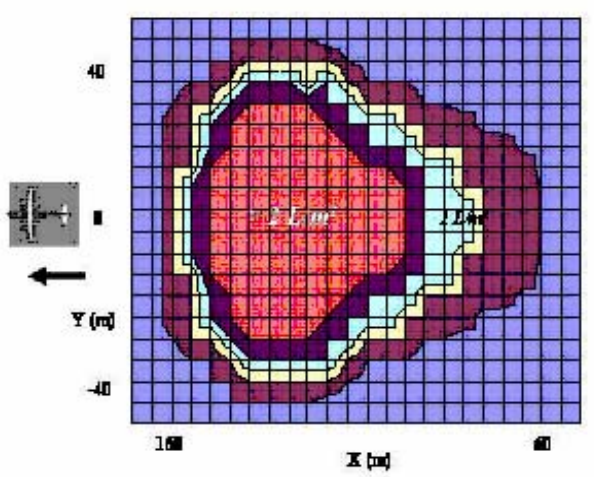

Fig. 9. Dropped water area based on the simulations by the ShinMaywa Model [7].

Table 1. The ratio of the amount of water reaching the ground against the total water amount dropped from the aircraft tank of PS-1, calculated from the previous data [6,7].

\begin{tabular}{|l|l|l|}
\hline & height (m) & height $(\mathbf{m})$ \\
speed $(\mathrm{km} / \mathrm{h})$ & 60 & 120 \\
\hline $138-185$ & $75 \%$ & $65 \%$ \\
\hline $204-222$ & $60 \%$ & $55 \%$ \\
\hline
\end{tabular}




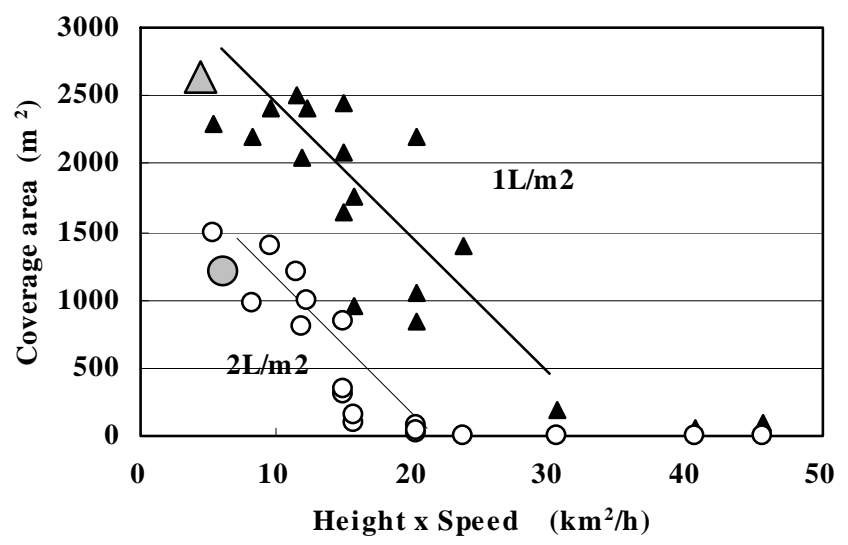

Fig. 10. Relationship between the product of the drop speed and the height and coverage water area with the density of 1 and $2 \mathrm{~L} / \mathrm{m}^{2}$, where the solid and blank signs are the data by PS-1 (8.5 tons) [6] and the gray symbols are those of US SP-2H (7.6 tons) [8].

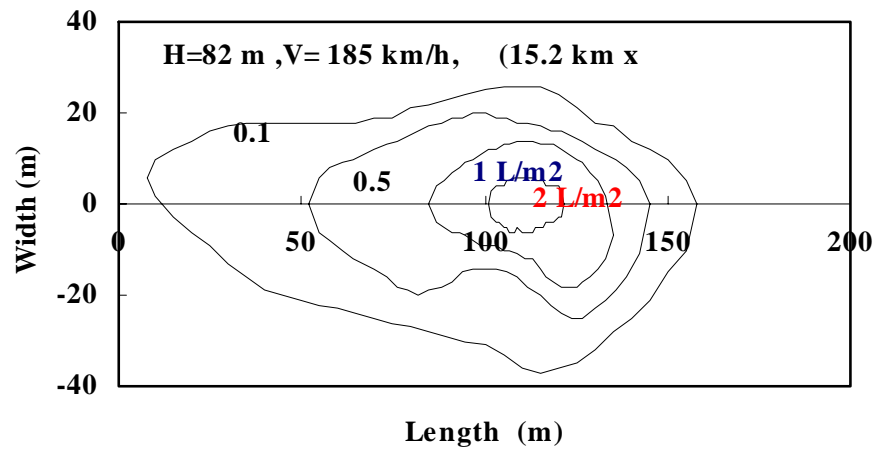

Fig. 11. Drop pattern characteristics of a flying boat PS-1 (8.5 tons of water) [6].

Currently, neither Japanese Fire Departments nor Self-Defense Forces have any fixedwing aircrafts particularly for aerial firefighting. However, in 1974, a series of experiments [4] were made to examine the patterns of dropping water from a flying boat, called ShinMaywa PS-1, carrying 8.5 tons of water scooped from the sea surface. The flight height of the flying boat PS-1 ranged from $31 \mathrm{~m}$ to $183 \mathrm{~m}$ and within 2.5 seconds, all water flowed out of the tank. Using the data of those tests, we investigated the water density dropped from a flying boat PS-1 and compared with those of Aero Union SP-2H [8] (fixed wing aircraft with 2,000-gallon tank in the body) from the United States, even though there exists a slight difference of water quantity between the two, namely 8.5 tons and vs. 7.6 tons. Figure 10 shows the relationship between the drop speed multiplied by the height and the coverage area of water by the density of 1 and $2 \mathrm{~L} / \mathrm{m}^{2}$. The data by US flight tests [8] are reasonably on the lines of the data by Japan, as shown by the gray symbols in the figure. Figure 11 shows the distribution of the water density on the ground, which is based on the data of the previous experiments of PS-1 [6], where the flight speed was $185 \mathrm{~km} / \mathrm{h}$ and the flight height was $82 \mathrm{~m}$. Together with Table 1, Figs. 10 and 11 give much useful information on the aerial fire fighting, indicating that 
the higher and the faster flight cause the dispersed water into mist and then the area of water density needed to protect the ignition by firebrands must reduce. Particularly, the flight at the altitude of $183 \mathrm{~m}$ (namely 600 feet) produces no area with the water density more than $1 \mathrm{~L} / \mathrm{m}^{2}$.

At this time, there are no experimental data of dropping water of 15 tons by a flying boat. However, the water amount of 15 tons is about twice more than that in the tests by PS-1 in Japan and SP-2H in USA and if the dropping water is repeated twice in the same area by the aircraft carrying 7 to 8 tons of water, the water density of $1 \mathrm{~L} / \mathrm{m}^{2}$ changes into $2 \mathrm{~L} / \mathrm{m}^{2}$ for a total amount of dropping water of 15 tons. Therefore, we may estimate a dropping water area at a resulting density of $2 \mathrm{~L} / \mathrm{m}^{2}$ for 15 tons of water, and $1.0 \mathrm{~L} / \mathrm{m}^{2}$ for about 8.5 tons. By this estimation, the dropping water area at a density of $2 \mathrm{~L} / \mathrm{m}^{2}$ with 15 tons of water is about $2,000 \mathrm{~m}^{2}$, which is close to the value of 2,000 to $3,000 \mathrm{~m}^{2}$, a result very close to those of simulations of both this study and the ShinMaywa study [7].

In the previous studies [9,10,11], we have studied the suppression effect of the firebrands in a large-scale forest fire, where the re is $100 \mathrm{~m}$ x $300 \mathrm{~m}$ area needed to drop water with the water density of $2 \mathrm{~L} / \mathrm{m}^{2}$. Thus, the total amount of dropping water was 60,000 litters, which correspond to 60 times of that for flight by a helicopter with 1-ton bucket. However, it corresponds to only 4 times that for a flight by a 15-ton flying boat. Both flow patterns of dropped water in the present simulations and experimental flights are similar and quite reasonable. However, there are some discrepancies between the simulated results and the experimental patterns. For example, the dropping water in the air often splits into mist, smaller blocks and large zones, such as in the pattern of so called Taylor breakup or surface erosion [12]. On the other hand, there is no such detailed water breakup subroutine in the present simulations. Another reason may be due to the coarse grids used in this study. Therefore, improved model is definitely needed in future studies, particularly in the mutual interaction dynamics between the water and the wind. Additionally, as mentioned above, the flow domain is too small, particularly in the flight direction. Therefore, further studies are needed to approach the real flow patterns and the detailed water distribution on the ground.

\section{CONCLUSIONS}

Since fire-fighting options are quite limited in large forest fires, the aerial fire fighting with water dumping from helicopters and aircrafts has been widely employed in the world. However, tests by real aircrafts would be too costly. Therefore, the possible patterns of water dumping from aircrafts as well as from helicopters were examined by CFD simulations, together with the investigation of the data in previous real aerial fire fighting tests. The simulated pattern of dropping water from a flying boat showed reasonable results, judging from the pattern in the previous fire fighting experiments. The simulated coverage area of water dumped from a flying boat is close to the experimental data, while the comparison between the Japanese experimental data and the US data on the coverage area of water dumped from aircrafts also indicate very close relationship. However, there are some discrepancies between the simulated results and the real ones on the detailed pattern of dropping water in air. Another reason for this may be due to the rather large grid sizes and much finer grids may be needed, as well as in the ground pattern by much larger numerical domain. Further studies are needed to approach the real flow patterns and the detailed water distribution on the ground, and must be based on model refinements on physical mechanisms not accounted for in the present simulation study. 


\section{REFERENCES}

[1] Satoh, K., Kuwahara, K., and Yang, K.T., "Experimental and Numerical Simulations of Flow Patterns of Dropping Water from Fire-fighting Helicopters," ASME-HTD, Vol. 5, pp. 57-64, Orlando, USA, (2000).

[2] Yamashita, K., Satoh, K., and Takemoto, A., "Report of Aerial Fire Fighting to Suppress City Fires,” Technical Report of National Research Institute of Fire and Disaster, No. 45, (1999).

[3] Kuwahara, K., and Komurasaki, S., "Unsteady Flow Simulation and its Visualization,” AIAA Paper 99-3405, (Houston), USA, (2000).

[4] Kuwahara, K., and Komurasaki, S., "Direct Simulation of a Flow Around an Airfoil," Proceedings of the 14th Symposium of Numerical Fluid Dynamics, JSCFD, B05-2, (Tokyo), pp. 1-7, (2000).

[5] Satoh, K., "A System to Predict Forest Fire Danger Rating and Fire Progression," Technical Report of National Research Institute of Fire and Disaster, No. 63, (2004).

[6] Nayuki, K., and Kasahara, N., "Report of Aerial Fire Fighting using Remodeled Flying Boat PS-1,” National Research Institute of Fire and Disaster, (1976).

[7] Maeda, I., "Technical Report of Flying Boat, PS-1,” ShinMaywa Industries, (2003).

[8] Solarz, P., and Jordan, C., "Ground Pattern Performance of the Aero Union SP2H,” 0057-2849-MTDC, USDA Forest Service, (2000).

[9] Satoh, K.I., Maeda, Kuwahara, K., and Yang, K.T., "Prediction of Forest Fire Danger Rating and Fire Progression, Part 9 Protection of Fire Spread by Aerial Water Drop,” Proceedings of 36th Japanese Safety Engineering Conference, pp. 83-86, Tokyo, Japan, (2003).

[10] Satoh, K., "Forest Fire Characteristics and Suppression Technique in Japan,” Proceedings of Forest Fire Suppression Techniques - 2004 Northern Asia Region International Symposium, pp. 50-72, Seoul, Korea, (2004).

[11] Satoh, K., Kuwahara, K., and Yang, K.T., “A Numerical Study of Forest Fire Progression and Fire Suppression by Aerial Fire Fighting," ASME-HTD, IMECE2004-60679, Anaheim, USA, (2004).

[12] Solarz, P., and Jordan, C., "Drop Testing Airtankers - A Discussion of the Cupand-Grid Method,” 5700 Aviation December 2000, 0057-2868-MTDC, US Department of Agriculture Forest Service, (2000). 
